\title{
UTILIZACIÓN DE LA PULPA DE CAFÉ ENSILADA COMO ALIMENTO DE OVINOS
}

Ing. Sandra Blandon Navarro

Correo: sandra.blandon@norte.uni.edu.ni

Responsable de Investigación

UNI-Norte
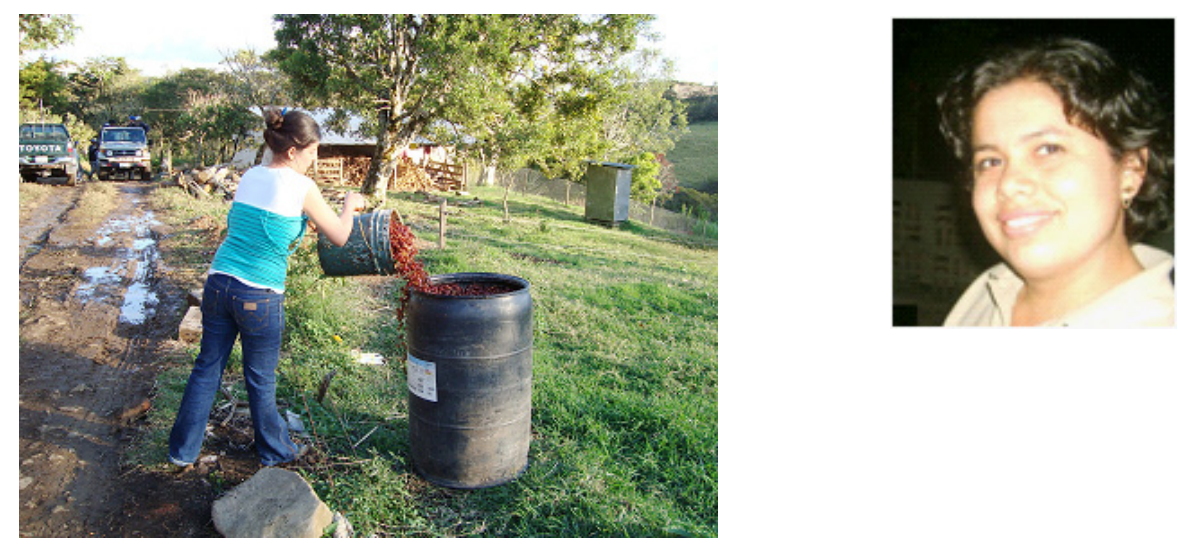

Preparación del ensilaje de la pulpa de café fresca.

\section{RESUMEN}

La pulpa de café es el subproducto que se obtiene de la operación de despulpado del fruto en uva, en los beneficios húmedos. Esta es rica en nutrientes y propicia el desarrollo de microorganismos y vectores de enfermedades cuando no recibe ningún tratamiento. El objetivo de este estudio fue evaluar el valor nutritivo de la pulpa de café ensilada en rumiantes (ovinos). La formulación se realizó utilizando 92.5\% de pulpa de café, 5\% de melaza, 1.5 $\%$ de urea y $1 \%$ de sal mineral. La mezcla resultante se introdujo en barriles, compactándolos para garantizar condiciones anaerobias durante 100 días. Posteriormente, se procedió a realizar el ensayo, utilizando 4 pelibueyes machos de $30 \mathrm{~kg}$ de peso vivo, los cuales fueron alojados en jaulas metabólicas individuales, con cuatro períodos experimentales de 15 días cada uno, considerando 10 días para la adaptación a las dietas experimentales y 5 días para la colección de muestras o toma de datos. Las variables a medir fueron el consumo de alimento, la digestibilidad aparente y la degradación ruminal. Los resultados obtenidos demostraron que la utilización de la pulpa de café en la alimentación de ovinos incrementó el consumo total de materia seca y no tuvo efecto sobre su digestibilidad aparente. Asimismo, presenta un alto potencial de degradación ruminal, demostrándose que casi toda puede ser fermentada en el rumen. Por lo tanto, la pulpa de café ensilada puede ser utilizada en la alimentación de ovinos, en época seca.

Palabras claves: pulpa de café, ensilada, digestibilidad, degradación ruminal, ovinos.

\section{INTRODUCCIÓN}

La pulpa de café representa aproximadamente el $40 \%$ del fruto y se obtiene como residuo del beneficio húmedo, en la etapa de despulpado. Si ésta no recibe ningún manejo adecuado, se constituye como un desecho sólido que al depositarse sobre terrenos o ser vertidos a los ríos, es fuente de malos olores y criaderos de vectores.

El alto contenido de agua de la pulpa de café, más de $75 \%$, hace costoso y difícil su manejo y conservación. Sin embargo, su composición química (Elías, 1978, citado por Ramírez et al.1999) está en favor de su uso como ingrediente en la dieta de los animales de la finca.

Lo anterior podría ser una solución al problema de la alimentación de verano del ganado en la zona norte, cuando los pastos escasean y los precios de los granos y los concentrados se encarecen. Este periodo coincide con la cosecha cafetalera en la cual se da la mayor producción de pulpa de café que podría ser utilizada en la alimentación animal. 


\section{MATERIALES Y MÉTODOS}

La investigación se llevó a cabo en las instalaciones de la UNI-Norte, ubicada en Estelí. Los animales experimentales fueron ovinos pelibuey, machos, con $30 \mathrm{~kg}$ de peso aproximadamente. Los pelibueyes se introdujeron en jaulas metabólicas individuales y se les suministró alimentos en base al consumo diario, incrementándose cuando no dejaban rechazo. Los tratamientos experimentales fueron T1: Paja de arroz más $0 \%$ de pulpa de café ensilada, T2: Paja de arroz más $10 \%$ de pulpa de café ensilada, T3: Paja de arroz más $20 \%$ de pulpa de café ensilada y T4: Paja de arroz má $30 \%$ de pulpa de café ensilada. Las variables medidas fueron el consumo de materia seca (MS), que se determinó por diferencia (MS ofrecida - MS rechazada), la digestibilidad aparente de la materia seca (MS), para la cual se recolectaron y pesaron las heces individualmente para obtener el peso total por día de heces de cada animal y la degradación ruminal de la MS, que se realizó utilizando la técnica de la bolsa propuesta por Orskov et al., (1980).

\section{RESULTADOS Y DISCUSIÓN.}

La utilización de la pulpa de café en la alimentación de ovinos incrementó el consumo total de materia seca (Figura $1 ; \mathrm{P}<0.05 ; \mathrm{r} 2=0.36$ ). Este incremento en el consumo probablemente se deba al menor contenido de fibra presente en la pulpa de café con respecto a la paja de arroz. Según Valdivia 2006, los alimentos que contienen un menor contenido de fibra inducen a un mayor consumo de alimento.

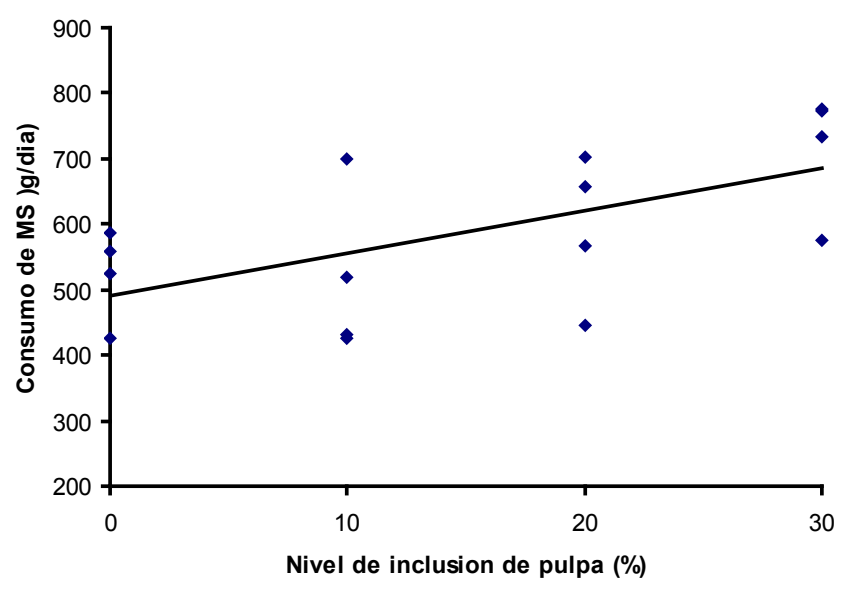

Figura 1. Consumo de MS en ovinos alimentados con paja de arroz y suplementados con pulpa de café. ( $\mathrm{Y}=$ $490.5+6.45 \mathrm{X} ; \mathrm{P}<0.05 ; \mathrm{r} 2=0.36$ )
Una causa que explica este efecto positivo es que al ensilaje de la pulpa se le adicionó urea por lo que mejoró el contenido de proteína cruda (PC) de la pulpa ensilada, por tanto aporta más nitrógeno al rumen, mejorando la fermentación ruminal.

Por otro lado, la suplementación con pulpa de café no tuvo efecto sobre la digestibilidad aparente de la MS en ovinos (Figura 2; $\mathrm{P}>0.05$ ). Esto podría ser sustentado por el valor de la tasa de degradación de la pulpa de café utilizada que fue de $9.09 \%$ /hora, que es dos veces mayor que la tasa de degradación de un forraje de buena calidad (Valdivia 2006) y es similar a la tasa de degradación de la MS de granos de cereales como el maíz reportado por Valdivia (2006) y tres veces mayor que la tasa de degradación de forrajes de mala calidad, como es el caso de la paja utilizada en el presente estudio y la tasa de degradación se ha asociado a incrementos en la tasa de pasaje de la digesta, así como con el consumo voluntario de alimento (Umunna et al., 1995, Valdivia y Ku 1996; Valdivia 2006)

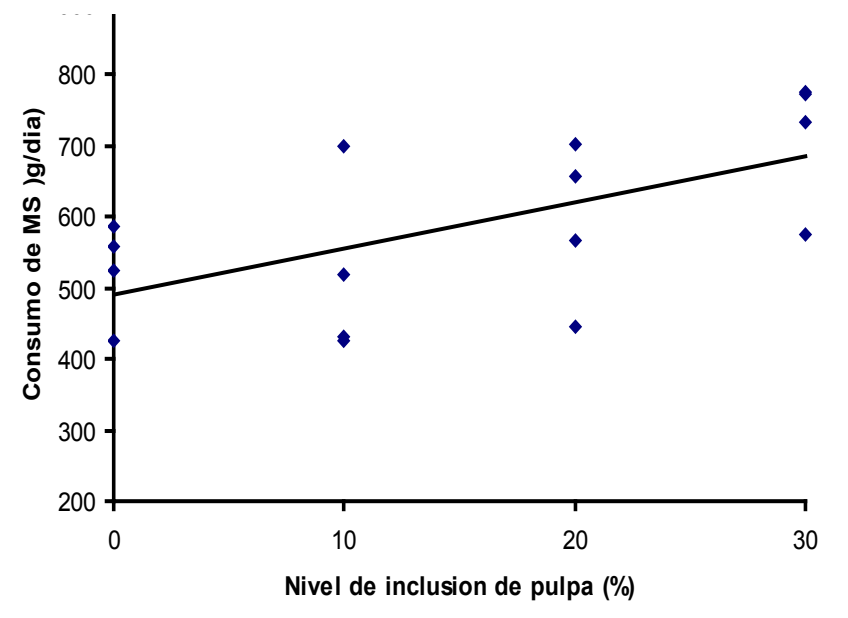

Figura 2. Digestibilidad aparente de la MS en ovinos alimentados con paja de arroz y suplementados con pulpa de café ensilada.

La pulpa de café presenta un alto potencial de degradación ruminal de la materia seca, demostrándose que casi toda puede ser fermentada en el rumen.

\section{CONCLUSIONES}

Con la adición de urea a la pulpa de café, se mejora el perfil de proteína cruda en el alimento, el cual es superior al de la pulpa fresca. 


\section{Revista EL HIGO}

Por su degradación ruminal y el efecto sobre el consumo total de MS, la pulpa de café ensilada es un buen suplemento para dietas de baja calidad como las que consumen los rumiantes en la época de secas en el norte de Nicaragua.

\section{REFERENCIAS}

- Orskov, E.R. Deb Hovell, F.D. y Mould, F. 1980. Uso de la técnica de la bolsa de nylon para la evaluación de alimentos. Producción Animal Tropical. 5:213-233.

- Ramírez, J.R., Pernía, R.D., Bautista, E.O., Clifford, M.N., Adams, M.R., 1999. Pulpa de Café ensilada. Universidad Nacional Experimental del Táchira (UNET), San Cristóbal, Venezuela, 139 p.

- Valdivia, V. 2006. Metabolismo del nitrógeno y función ruminal en vacas cruzadas Bos taurus x Bos indicus en un sistema silvopastoril con Leucaena leucocephala. Tesis Doctoral. Universidad Autónoma de Yucatán, México. pp 189

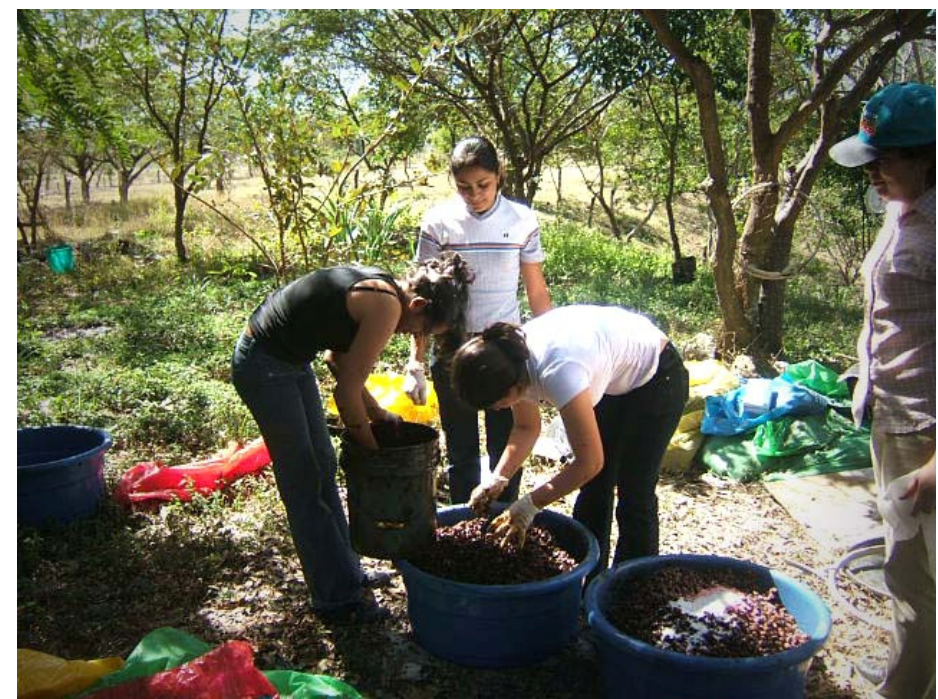

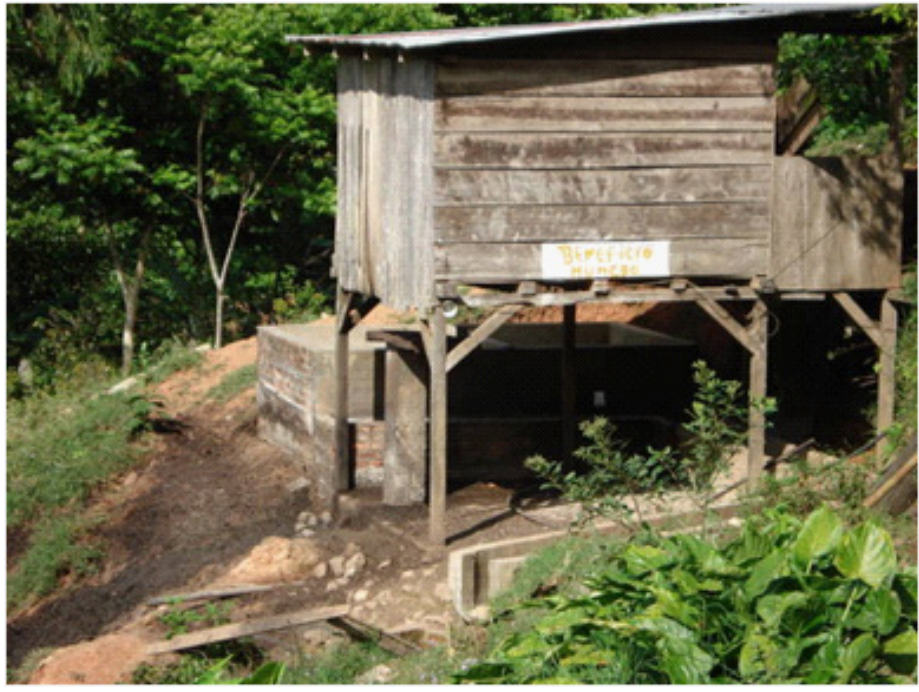

Beneficio húmedo en finca

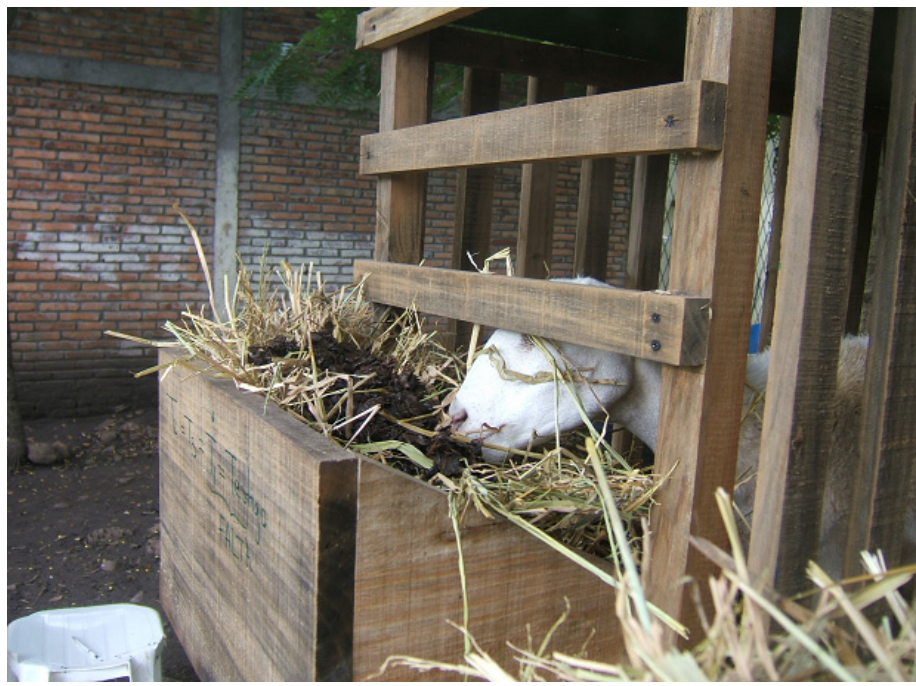

Pelibueyes alimentándose con pulpa de café ensilada y paja de arroz

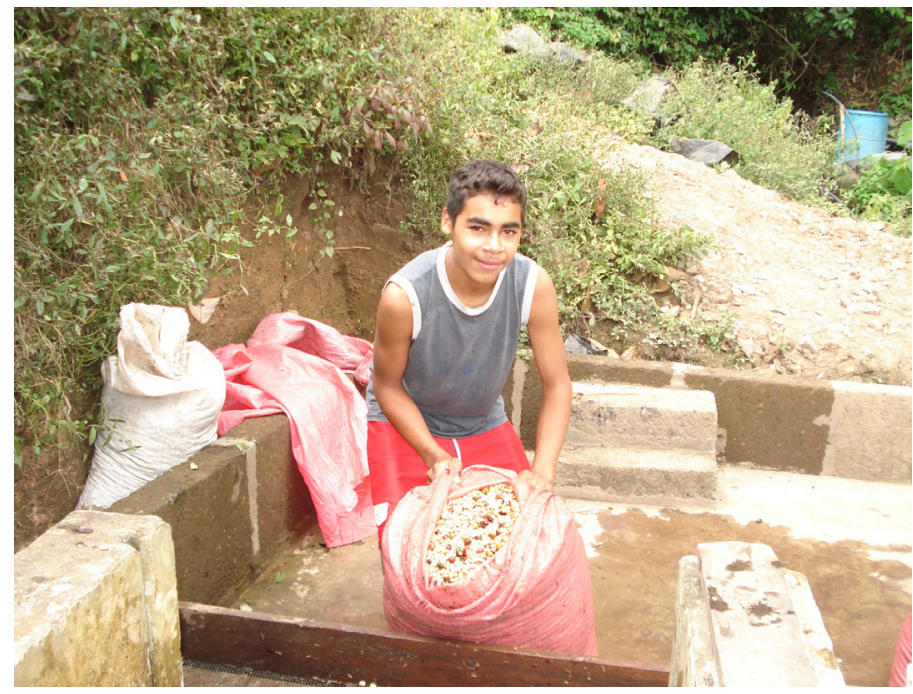

